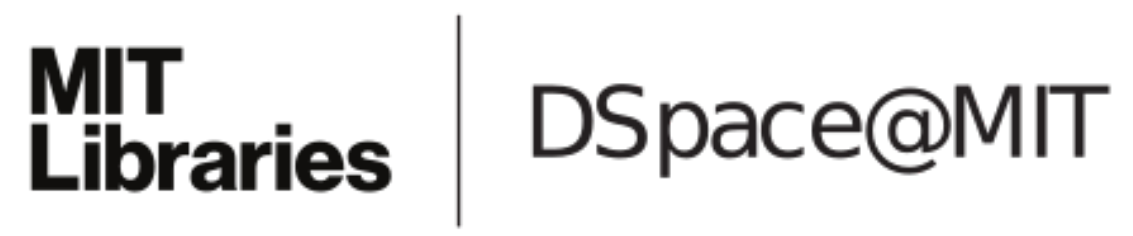

MIT Open Access Articles

Pool boiling of refrigerants over
nanostructured and roughened tubes

The MIT Faculty has made this article openly available. Please share how this access benefits you. Your story matters.

As Published: $10.1016 / j . j$ ijheatmasstransfer.2020.120387

Publisher: Elsevier BV

Persistent URL: https://hdl.handle.net/1721.1/136062

Version: Author's final manuscript: final author's manuscript post peer review, without publisher's formatting or copy editing

Terms of use: Creative Commons Attribution-NonCommercial-NoDerivs License 


\title{
Pool boiling of refrigerants over nanostructured and roughened tubes
}

\section{This is the PREPRINT version of this article. The final, published version of the article can be found at: https://doi.org/10.1016/j.ijheatmasstransfer.2020.120387}

\author{
Bradley D. Bock ${ }^{a}$, Matteo Buccib, Christos N. Markides ${ }^{c}$, John R. Thome ${ }^{d}$ and Josua P. Meyera* \\ ${ }^{a}$ Department of Mechanical and Aeronautical Engineering, Faculty of Engineering, the Built Environment and IT, \\ University of Pretoria, Pretoria, South Africa \\ ${ }^{b}$ Department of Nuclear Science and Engineering, Massachusetts Institute of Technology (MIT), \\ Cambridge, MA, 02139, USA \\ 'Clean Energy Processes (CEP) Laboratory, Department of Chemical Engineering, Imperial College London, London, SW7 2AZ, UK \\ ${ }^{d}$ Institute for Multiscale Thermofluids, School of Engineering, University of Edinburgh, Edinburgh, United Kingdom and JJ Cooling Innovation Sàrl, \\ Lausanne, Switzerland
}

\begin{abstract}
This study investigated the heat transfer performance of three nanostructured surfaces and two plain surfaces: one roughened and one polished during the saturated pool boiling of refrigerants R-134a at 5 and $25{ }^{\circ} \mathrm{C}$ and R-245fa at $20^{\circ} \mathrm{C}$. Nanocoatings were applied to polished copper tubes through a layer-by-layer (LbL) process that deposited silica nanoparticles, a chemical oxidation process where an intertwined mat of sharp copper oxide (CuO) structures were generated and a commercial nanocoating process (nanoFLUX). A polished copper tube and a roughened copper tube were tested as comparison cases. All tubes were tested in the horizontal position in pool boiling over heat fluxes of 20 to $100 \mathrm{~kW} / \mathrm{m}^{2}$, followed by a further increase in heat flux in an attempt to reach critical heat flux. The tubes were internally water heated and Wilson plots were conducted to characterise the internal heat transfer characteristics. The nanoFLUX surface had the highest heat transfer coefficients, the LbL and polished surfaces had the lowest heat transfer coefficients, and the $\mathrm{CuO}$ and roughened surfaces had intermediate heat transfer coefficients. The nanoFLUX surface had between 40 and 200\% higher heat transfer coefficients than those of the polished tubes. Both roughened tubes and nanocoated tubes showed typical exponentially increased heat transfer coefficients as heat flux was increased. However, the nanoFLUX and CuO surfaces displayed more heat flux sensitivity compared with the other surfaces. The nanoFLUX surfaces outperformed the other nanostructured surfaces due to a higher nucleation site density and outperformed the roughened tube due to a unique heat transfer mechanism. The nanoFLUX and $\mathrm{CuO}$ surfaces also experienced reduced critical heat flux compared with plain surfaces, thought to be caused by the trapping of vapour in the fibrous nanostructures, resulting in reduced wetting in the Cassie-Baxter state.
\end{abstract}

Keywords: pool boiling; nanocoating; nanostructures; roughness; critical heat flux; heat transfer coefficients.

\section{Nomenclature}

$\begin{array}{ll}a & \text { Fitting coefficient } \\ C & \text { Wilson plot modifier coefficient } \\ c_{p} & \text { Specific heat capacity } \\ D & \text { Diameter } \\ f & \text { Friction factor } \\ h & \text { Heat transfer coefficient } \\ K & \text { Heat transfer enhancement ratio } \\ k & \text { Thermal conductivity }\end{array}$

\footnotetext{
${ }^{*}$ Corresponding author

Email address: josua.meyer@up.ac.za
} 


\begin{tabular}{|c|c|}
\hline$m$ & Fitting exponent \\
\hline$\dot{m}$ & Mass flow rate \\
\hline$n$ & Nucleation site density \\
\hline$P r_{w}$ & Prandtl number of heating water, $\frac{c_{p, w} \mu_{w}}{k_{w}}$ \\
\hline$p_{r}$ & Reduced pressure \\
\hline$q$ & Heat flux \\
\hline$R_{a}$ & Arithmetic mean roughness \\
\hline$R$ & Thermal resistance \\
\hline$R e_{w}$ & Reynolds number of water in tube, $\frac{4 m_{w}}{\pi\left(D_{i}+D_{\text {probe }}\right) \mu_{w}}$ \\
\hline$T$ & Temperature \\
\hline$U$ & Overall heat transfer coefficient \\
\hline$x$ & Coordinate dimension along the length of the tube \\
\hline$\mu$ & Dynamic viscosity \\
\hline \multicolumn{2}{|l|}{ Subscripts } \\
\hline$h$ & Hydraulic \\
\hline$i$ & Inner \\
\hline measured & Experimentally measured \\
\hline$o$ & Outer \\
\hline plain & Plain surface \\
\hline pol & Relative to the polished tube \\
\hline probe & Heating water temperature probe \\
\hline sat & Saturated refrigerant \\
\hline surf & Surface enhancement relative to polished surface \\
\hline$w$ & Water \\
\hline ws & Wall superheat \\
\hline wall & Tube wall \\
\hline \multicolumn{2}{|l|}{ Abbreviations } \\
\hline$A F M$ & Atomic force microscopy \\
\hline CHF & Critical heat flux \\
\hline $\mathrm{CuO}$ & Copper oxide \\
\hline HTC & Heat transfer coefficient \\
\hline$L b L$ & Layer-by-layer \\
\hline SEM & Scanning electron microscope \\
\hline $\mathrm{SiO}_{2}$ & Silicon dioxide/Silica \\
\hline $\mathrm{TiO}_{2}$ & Titanium dioxide \\
\hline
\end{tabular}

\section{Introduction}

Enhancement of boiling heat transfer is a continued goal of heat transfer research in order to enable or promote a diverse range of technologies. It can lead to more efficient and economically favourable energy systems, from small footprint refrigeration systems to more affordable solar power plants [1]. The passive enhancement of boiling through surface modification has been conducted for decades through the addition of microstructures such as fins to increase the heat transfer area or re-entrant cavities [2], as well as the roughening of surfaces [3] to increase nucleation site density. Nanostructures offer the opportunity to passively modify and enhance boiling through new mechanisms not previously available, with a wide variety of structures created to meet this end [4-6].

Nanostructured surfaces can improve or worsen heat transfer compared with plain surfaces. Some of the earliest creations of nanostructured surfaces were through the surface deposition of nanoparticles during the boiling of nanofluids. At times, this produced improved heat transfer, with increased roughness and thus increased nucleation site densities, or worsened heat transfer with nanoparticles filling roughness or adding a low thermal conductivity layer on top of the surface [7]. Subsequently, various nanostructures were created through chemical and mechanical means with varying influences on boiling heat transfer [4,5]. Improvements were attributed to increased roughness of the surfaces, capillary pumping of liquid to nucleation sites by wickable surfaces, positively modifying bubble dynamics, and surfaces with lower wettability activating a greater number of nucleation sites [4-6]. Deterioration in 
heat transfer was typically attributed to lower nucleation site densities caused by either lower surface roughness or the flooding of nucleation sites through increased wettability $[5,6,8]$.

The critical heat flux (CHF) of a surface was generally shown to increase with the presence of nanostructures compared with plain surfaces when boiling water [4,5]. This improved CHF performance was attributed to mechanisms such as improved wettability of the surfaces [6], increased contact line length of the bubble due to increased roughness [9] and improved wickability of the surfaces [10-12], all delaying the creation of a vapour blanket. Given the wide ranges of nanostructured surfaces produced, it is possible that the relevance of these mechanisms varies for each type of surface.

Previous studies were conducted on the surfaces used in this study, but only with water at atmospheric pressure on flat surfaces or wires. The CuO surface used in this study was found to produce either lower [9] or equivalent heat transfer [13] to plain surfaces when boiling water at atmospheric pressure. Rahman et al. [13] conducted a water pool boiling study where infrared high-speed thermometry was used to measure the time-dependent heat flux distribution at the bubble footprints. They observed that the bubble base diameters were larger on the $\mathrm{CuO}$ surface than on the plain surface. The $\mathrm{CuO}$ surface also had a lower bubble departure frequency and lower nucleation site density than those of the plain surface, despite similar heat transfer coefficients (HTCs). Dryout was observed to be reduced underneath the growing bubbles on the $\mathrm{CuO}$ surface, with the evaporation of liquid underneath the bubbles supplied by capillary wicking put forward as the cause. This provided an additional heat flux pathway compared with the plain surface, increasing heat transfer at nucleation sites. The CuO surface was found to increase the CHF [9,13], with the authors suggesting that this was caused by the high surface roughness providing a pinning force to prevent dryout [9] or the high wickability of the surface supplying fresh liquid that prevented the onset of dryout and the subsequent formation of a vapour blanket [13].

The LbL nanoparticle coating method implemented in this study was used to produce hydrophilic and hydrophobic coatings for the pool boiling of water on nickel wires [14]. Compared with the uncoated wire, the heat transfer improved for the hydrophobic wire and worsened for the hydrophilic wire, despite the coating producing similar roughness. Images show that, compared with the uncoated wire, the hydrophobic wire had more nucleation sites and the hydrophilic wire had fewer nucleation sites. Therefore, the wettability of the surfaces appeared to play a major role in the heat transfer, either flooding or activating cavities. However, the CHF was increased by both the hydrophobic and hydrophilic coating and increased with nanocoating layer thickness. Further studies on LbL surfaces by O'Hanley et al. [15] found no significant influence of the wettability of plain smooth surfaces on the CHF, nor the surface roughness of plain or nanocoated surfaces. However, the porosity and wettability of nanostructured surfaces were found to influence the $\mathrm{CHF}$, with hydrophobic porous structures decreasing the CHF and hydrophilic porous structures increasing the CHF. O'Hanley et al. [15] concluded that capillary wicking appeared to play a significant role in the CHF. Tetreault-Friend et al. [16] found that there was an optimum layer thickness for maximum CHF enhancement by the porous LbL surfaces. They proposed that competition between capillary wicking and conduction heat transfer within the porous layer determined the optimal porous layer thickness and subsequent magnitude of CHF enhancement.

Studies of the pool boiling of refrigerants or similar organic fluids on nanostructured surfaces are relatively rare, as evident in the reviews of the topic [4-6]. Heat transfer was worsened when Trisaksri and Wongwises [17] added titanium dioxide $\left(\mathrm{TiO}_{2}\right)$ nanoparticles to refrigerant $\mathrm{R}-141 \mathrm{~b}$ for the pool boiling on a cylindrical copper tube. Considering that their tube was sandblasted and thus had a relatively high roughness ( $R_{a}$ of $\left.3.14 \mu \mathrm{m}\right)$, it is likely that the nanoparticles deposited on the surface reduced the roughness and number of active nucleation sites. The heat transfer of plain surfaces was improved in some studies when nanostructures were added to the pool boiling of refrigerants [18] and Fluorinerts [19-21], and the flow boiling of Fluorinerts [22], with authors attributing this to increased nucleation site density caused by the particular nanocoatings used. In some cases, the nanostructures only improved the heat transfer at higher heat fluxes, while at lower heat fluxes, the plain surfaces were comparable or better than the nanostructured surface [12,23].

The influence of nanostructured surfaces on the CHF when boiling organic fluids has been mixed. The CHF was increased compared with that of plain surfaces in some studies of pool boiling of Fluorinerts [19,20] with Kumar et al. [20] having measured that the copper nanowires used in their study lowered the contact angle of FC- 72 from $15^{\circ}$ to less than $5^{\circ}$. They attributed the enhanced CHF to improved wetting, combined with capillary wicking, i.e. providing liquid replenishment to nucleation sites. Liu et al. [12] found that the CHF stayed the same in the pool boiling of n-pentane on a nanoparticle-coated surface, while the CHF improved for combined nano-microstructured surfaces. High-speed videos showed that the nanoparticle-coated and plain surfaces had similar droplet-spreading abilities, while the nano-microstructured surfaces showed improved droplet spreading. This metric of liquid spreading used 
by Liu et al. [12] could be related to the wickability of the surface, considering that both liquid spreading and the capillary wicking of liquid involve adhesive forces between the liquid and the surfaces.

The CHF decreased compared with that of plain surfaces for studies of nanowire-coated surfaces in the flow boiling [22,24] and pool boiling [23] of Fluorinert FC-72 by values of between 20 and 30\%, despite two of the studies reflecting improvements in CHF when boiling the nanowire-coated surfaces in water [22,24]. Shin et al. [24] and Zimmermann et al. [23] measured FC-72 contact angles that increased by between 5 and $7^{\circ}$ when nanostructures were added to a plain surface, which the authors suggested was part of the reason for the reduced CHF of these surfaces in FC-72. However, Kim et al. [22] recorded a reduction in the CHF through the addition of nanowires in FC-72 despite the nanowires lowering the contact angle by $3^{\circ}$. This lowered CHF was also attributed to the reduced wicking ability of FC-72 compared with water due to its lower surface tension [22,24], as well as the possibility that nanowires hindered vapour removal from the surface [23,24].

Most pool boiling heat transfer studies on nanostructured surfaces were conducted with water on flat plates at atmospheric pressure [4-8,25]. Very little work has been done on the outside surface of circular tubes with dimensions similar to those used in commercial systems such as chillers. For highly wetting fluids, such as refrigerants, the mechanisms involved in nanostructured surface boiling are thus not well understood. To understand the potential of nanostructured surfaces in the refrigerant industry, this study conducted pool boiling tests with refrigerants R-134a and R-245fa on the outside of horizontal water-heated tubes at three reduced pressures with three nanostructured surfaces and two plain surfaces (one roughened and one polished). The pool boiling data of the polished and roughened surfaces in R-134a has been presented previously in Bock et al. [26].

\section{Experimental and tube setup}

\subsection{Experimental setup}

The testing took place according to the detailed description given in Bock et al. [26] and is briefly described here. A schematic of the test apparatus is shown in Figure 1. Tubes were placed in a test chamber and submerged in a pool of liquid refrigerant. Vapour produced during boiling of the refrigerant travelled under the action of buoyancy to the overhead condenser, where it was condensed and returned to the bottom of the apparatus, from where a refrigerant pump returned the liquid to the liquid pool in the test chamber.

Tubes were internally heated by water for a heated length of $568 \mathrm{~mm}$ and tested individually. The saturation pressure of the refrigerant was measured with pressure transducers and compared with thermocouple readings to ensure that minimal non-condensable gases were present.

The temperature profile of the water along the length of the tube was measured with the aid of a custom-developed thermocouple probe placed inside the tubes. This temperature profile was used to calculate the instantaneous heat flux at the centre of the tube.

The test chamber was fitted with windows on the front and back, which allowed for visual access. The boiling of the tubes was recorded with a Photron FASTCAM Mini UX100 high-speed video camera at $2000 \mathrm{fps}$ with the aid of front and back lighting with GS Vitec PT high-power white LEDs and a Tonica AT-X $100 \mathrm{~mm} 2.8$ macro lens.

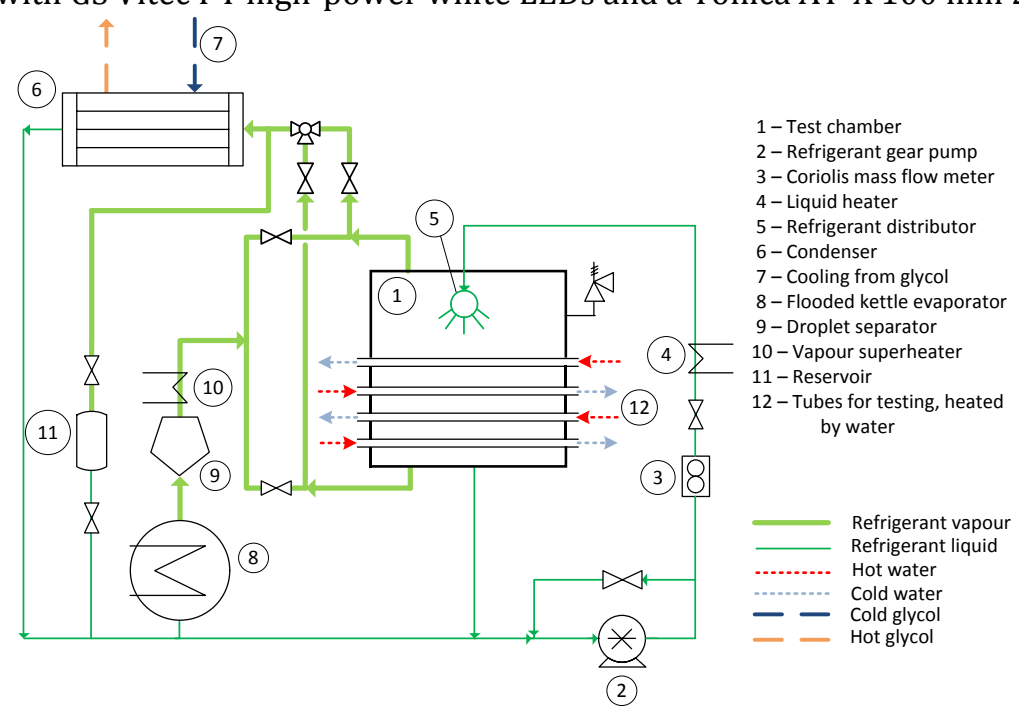

Figure 1: Schematic of the refrigerant loop, test chamber and test section tubes (12) (taken from Bock et al. [26]) 
Refrigerants and operating conditions were chosen so that tests could be conducted across a wide range of reduced pressure values, while operating within the capabilities of the experimental facility. Reduced pressure is a key correlating parameter within a number of widely used pool boiling correlations to account for fluid influences in pool boiling heat transfer based on the theorem of corresponding states $[27,28]$.

Thus, the lower-pressure refrigerant R-245fa and the higher-pressure refrigerant R-134a were chosen to allow for a range of reduced pressure values. Tests were conducted at three different reduced pressure values, namely a reduced pressure, $p_{r}$, of 0.034 in refrigerant R-245fa at a saturation temperature of $20{ }^{\circ} \mathrm{C}$ and a $p_{r}$ of 0.086 and 0.160 in refrigerant R-134a at saturation temperatures of 5 and $25^{\circ} \mathrm{C}$, respectively.

The nominal heat flux range was 20 to $100 \mathrm{~kW} / \mathrm{m}^{2}$. The tube was subjected to a heat flux greater than $100 \mathrm{~kW} / \mathrm{m}^{2}$ at the beginning of a test to ensure no hysteresis influence. After the heat flux range was completed, the heat flux was increased to the maximum value that the experimental rig could produce to determine if the CHF could be reached.

\subsection{Test section surfaces}

Tests were conducted on a polished, a roughened and three nanostructured copper tubes with outer diameters of $19.05 \mathrm{~mm}$ (nominally 3/4" tubing). The polished and roughened surfaces were prepared by sanding a commercially available smooth hard drawn copper tube along its longitudinal axis with grit 1200 and 40 sandpapers respectively. The resulting mean arithmetic roughness, $R_{a}$, measured across the grain with a diamond tip profilometer (Mitutoyo SJ Surftest 210) was 0.12 and $1.37 \mu \mathrm{m}$, respectively. Further details can be found in Bock et al. [26].

Three nanocoatings were applied to copper tubes that had first been polished with grit 1200 sandpaper. The LbL coating process was developed by Cebeci et al. [29] with the tube alternatively dipped in a silica $\left(\mathrm{SiO}_{2}\right)$ nanoparticle solution and a polymer solution. This process was repeated 50 times to create a nominally 50 -layer thick coating. This was achieved with an automated dipping machine with the tube constantly axially rotated to ensure an even distribution of nanoparticles. The $\mathrm{CuO}$ nanocoated surface was achieved through a chemical oxidation process by the immersion of the tube in an alkali solution for 10 minutes and rotated manually to ensure an even distribution of nanostructures. The alkali solution is described by Nam and Ju [30] as their Type I solution . The nanoFLUX® surface is a commercial process.

Scanning electron microscope (SEM) images of all three nanostructured surfaces are shown in Figure 2. The polished and roughened tubes had longitudinal grooves along the length of the tube, with the grooves of the roughened surface being larger than those of the polished surface. The LbL surface had very small surface structures compared with the other nanocoatings, with a layer thickness of approximately 0.4 to $0.5 \mu \mathrm{m}$. It can be noted in the images of the LbL coating that the surface was not very porous, and the nanoparticles appeared to clump together. The $\mathrm{CuO}$ and nanoFLUX surface both produced an intertwined fibrous mat of sharp needle-like or dendritic extrusions. The $\mathrm{CuO}$ coating was approximately 2 to $3 \mu \mathrm{m}$ thick. The nanoFLUX extrusions is shown on a larger scale than those of the other surfaces. The SEM images of samples taken around the circumference of the tubes showed similar nanostructures, suggesting that an even coating was applied to all the tubes.

The roughness of the nanostructured surfaces could not be measured by the profilometer as the tip scratched the coatings. Atomic force microscopy (AFM) was used to measure the surface profiles, with the results of the polished and LbL surfaces shown in Figure 3. The AFM scans show the grooves on the polished surface and show that the nanoparticles of the LBL coating process appear to have, at times, clumped together to form local valleys and troughs. The AFM scans of the nanoFLUX and CuO surfaces failed to produce realistic images when compared with the SEM information due to the high aspect ratio of these surface structures.

The nanostructured coatings added minimal thermal resistance to the tubes, because the LbL and CuO coatings increased the total thermal resistance of the tube wall by less than $0.1 \%$, based on thermal resistance calculations using the thicknesses given in Figure 2 and assuming that they were solid layers of $\mathrm{SiO}_{2}$ and CuO, respectively.

The $\mathrm{CuO}$ nanocoated surface showed significant changes to its wettability during the study. Immediately after coating the tube, the $\mathrm{CuO}$ surface was very hydrophilic, with contact angles measured with water in air of less than $5^{\circ}$. Once testing started, the surface showed very low HTCs, most likely due to the high wettability flooding potential nucleation sites. Over the initial two hours of testing, the HTCs increased and then stabilised for the remainder of the study. Subsequent testing of the contact angle of water in air of the $\mathrm{CuO}$ surface showed that the surface had become hydrophobic, with contact angles now greater than $90^{\circ}$. The change of the wettability of the $\mathrm{CuO}$ surface in water was likely through the adsorption of the organic refrigerant onto the surface as described previously [31,32]. All data recorded in this study was after boiling the surfaces for a number of hours in refrigerant to ensure they were all in a stable 'aged' condition. 


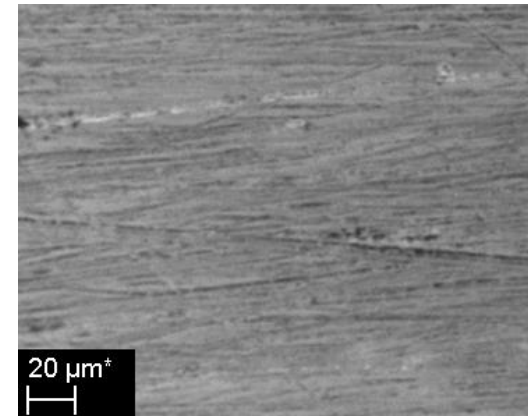

(a) Polished

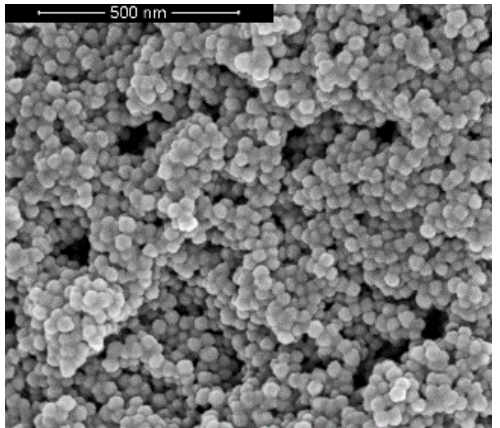

(c) LbL - top view

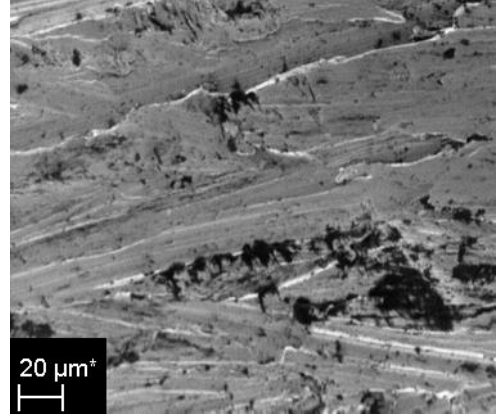

(b) Roughened

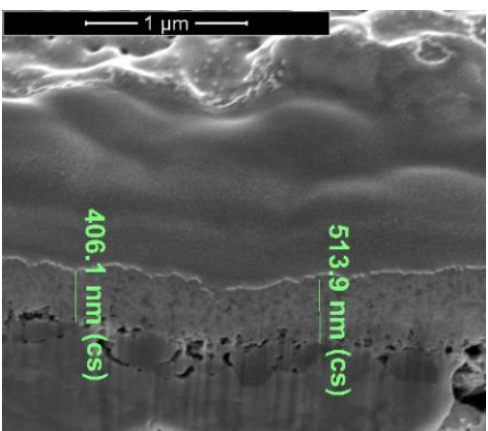

(d) LbL - cross-section

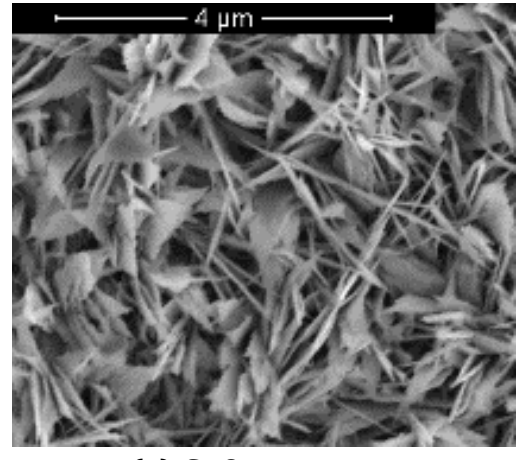

(e) $\mathrm{CuO}$ - top view

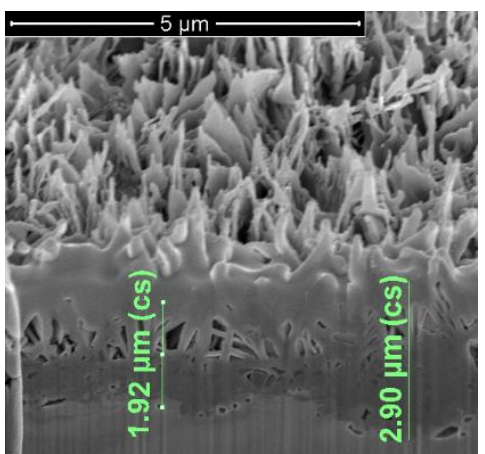

(f) $\mathrm{CuO}$ - cross-section

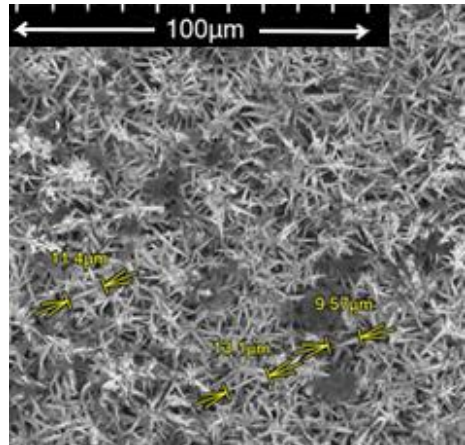

(g) nanoFLUX

Figure 2: SEM images of test section surfaces ( $a$ and $b$ taken from Bock et al. [26] )

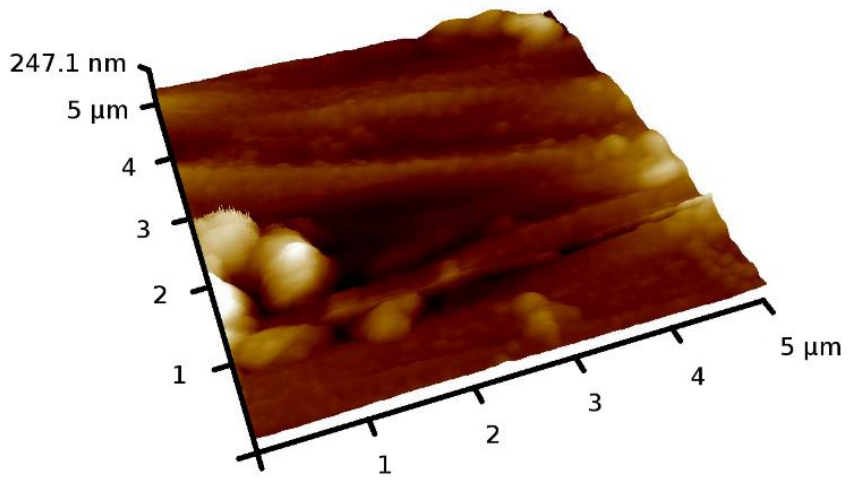

(a) Polished

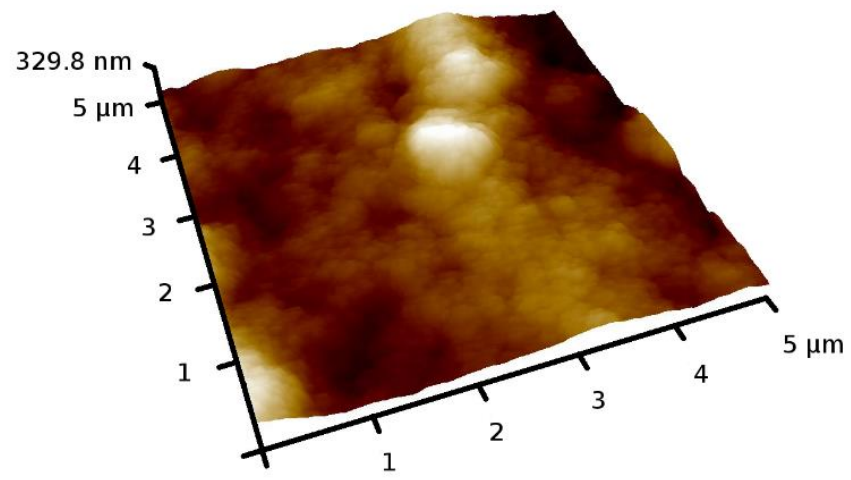

(b) LbL

Figure 3: AFM scans of test section surfaces 
Contact angles of approximately $20^{\circ}$ were measured on all surfaces after ageing with R-245fa in air at atmospheric temperatures of approximately $25^{\circ} \mathrm{C}$ with the aid of the images from a high-speed video camera analysed with a lowbond axisymmetric drop shape algorithm [33] implemented in the ImageJ software program [34]. The rapid evaporation of the fluid introduced significant noise. No statistically significant differences between the contact angles of the surfaces could therefore be detected with this measurement method. The refrigerant was thus able to wet all the surfaces and was likely in the Wenzel wetting state [35] at these test conditions. It should be noted that previous tests conducted with the $\mathrm{CuO}$ surface in water-boiling studies had been in a superhydrophilic state (contact angle of $\sim 0^{\circ}$ ) [13].

In this study, the $\mathrm{CuO}$ surface was still well wetted by the refrigerant, but to a lesser extent (contact angle of $\sim 20^{\circ}$ ). The measured contact angles of all the surfaces in the aged condition for water in air are shown in Table 1 . The CuO and nanoFLUX surfaces were hydrophobic to water with the needle-like fibrous structures on the surfaces likely trapping air beneath the droplet causing wetting in the Cassie-Baxter state [36].

Table 1: Contact angles of water on aged surfaces

\begin{tabular}{lc}
\hline Test section surface & $\begin{array}{c}\text { Average contact angle } \\
\text { (Average } \pm \text { standard deviation) } \\
{\left[{ }^{\circ}\right]}\end{array}$ \\
\hline Polished & $78 \pm 4$ \\
Roughened & $85 \pm 3$ \\
LbL & $52 \pm 7$ \\
CuO & $122 \pm 24$ \\
nanoFLUX & $161 \pm 16$ \\
\hline
\end{tabular}

The $\mathrm{CuO}$ and nanoFLUX surfaces were shown to wick liquid, with refrigerant dripped onto the $\mathrm{CuO}$ and nanoFLUX surfaces under isothermal conditions showing a wetted region adjacent to the droplet front. This was not seen on any of the other surfaces tested. It appears that the LbL surface in this study did not produce a wickable porous surface as in the previous studies in which it had been used, with the AFM scans shown in Figure 3 suggesting that the clumping of the nanoparticles could have limited the porosity produced.

\section{Data reduction and uncertainties}

The data reduction methodology used has already been described in detail by Bock et al. [26] and is therefore only described very briefly here.

\subsection{Local heat flux}

The temperature profile of the heating water was measured and used to calculate the local heat flux, $q$, at the midpoint of the tube test section length by

$$
q=\frac{\dot{m}_{w} c_{p, w}}{\pi D_{o}} \frac{d T_{w}}{d x}
$$

where, $\dot{m}_{w}$, was the measured water mass flow rate, $D_{o}$, was the measured outer diameter of the tube tested and, $d T_{w} / d x$, was the measured temperature gradient at the midpoint of the tube estimated with a second-order polynomial fit through the measured temperature profile of the water along the length of the tube.

The specific heat capacity of the water, $c_{p, w}$, was estimated using REFPROP 8, a fluid thermodynamic and transport property database [37].

\subsection{Internal heat transfer coefficient}

The internal HTC, $h_{i}$, was calculated from

$$
h_{i}=C_{i} \frac{(f / 8)\left(R e_{w}-1000\right) P r_{w}}{1+12.7(f / 8)^{0.5}\left(P r_{w}^{2 / 3}-1\right)}\left(\frac{k_{w}}{D_{h}}\right)
$$


which assumes the form of the Gnielinski correlation [38] with a modifying coefficient, $C_{i}$, to account for any differences between the Gnielinski correlation and the tested tube, such as the presence of the temperature probe. The coefficient, $C_{i}$, was determined through an experimental Wilson plot study. The friction factor, $f$, was calculated from Petukhov's correlation [39].

The Reynold's number, $R e_{w}$, Prandlt number, $P r_{w}$, and thermal conductivity, $k_{w}$, of the heating water was estimated using the measured temperature of the heating water at the midpoint of the tube and the resulting fluid properties based on REFPROP 8 . The hydraulic diameter, $D_{h}$, was given by, $D_{i}-D_{\text {probe }}$, namely the difference between the inner diameter of the tube, $D_{i}$, and outer diameter of the temperature probe, $D_{\text {probe }}$.

\subsection{External heat transfer coefficient}

The external HTC of the tube at its centre point along its length, $h_{o}$, was calculated by

$$
h_{o}=\left(\frac{1}{U_{o}}-R_{\text {wall }}-\frac{1}{h_{i}} \frac{D_{o}}{D_{i}}\right)^{-1}
$$

where, $R_{\text {wall }}$, is the calculated wall thermal resistance.

The overall HTC, $U_{o}$, was calculated by

$$
U_{o}=\frac{q}{T_{w}-T_{s a t}}
$$

where, $T_{w}$, was the measured heating water temperature at the midpoint of the tube and, $T_{s a t}$, was the calculated saturation temperature of the refrigerant from REFPROP 8 based on the measured saturation pressure of the refrigerant.

\subsection{Enhancement relative to a polished tube}

The surface enhancement of pool boiling heat transfer relative to a polished tube, $K_{\text {pol }}$, was calculated by

$$
K_{p o l}=\frac{h_{o}}{h_{o, p o l}}
$$

where $h_{o, p o l}$ is the interpolated HTC of the polished tube based on a fourth-degree polynomial fit to the measured HTCs.

\subsection{Nucleation site density}

The nucleation site density was determined from high-speed videos taken of the boiling surfaces at a heat flux of $20 \mathrm{~kW} / \mathrm{m}^{2}$ with R-245fa at a saturation temperature of $20{ }^{\circ} \mathrm{C}$. The nucleation sites were identified manually by zooming in on a high-speed video and forwarding and reversing the playback to identify where bubbles originated. The nucleation site density could not be determined at higher heat fluxes with R-245fa or with any R-134a tests because the greater bubble nucleation brought about by these conditions caused an increased number of passing bubbles that obscured the nucleation sites.

\subsection{Uncertainties}

The expanded standard uncertainties of the probes were calculated in accordance with Dunn [40], and the combined standard uncertainties of the calculated quantities were calculated in accordance with JCGM 100:2008 [41]. The resulting average uncertainties across the range of experiments for the heat flux and HTC were 10 and $28 \%$, respectively, with the respective heat flux and HTC maximum uncertainties of 29 and $61 \%$ found at a heat flux of $20 \mathrm{~kW} / \mathrm{m}^{2}$ and respective minimum uncertainties of 2 and $9 \%$ found at a heat flux of $100 \mathrm{~kW} / \mathrm{m}^{2}$. 


\section{Results and discussion}

\subsection{Heat transfer coefficients}

The measured external HTCs, $h_{o}$, on the outside of the tube where boiling occurred as a function of the heat flux over the polished, roughened and nanostructured tubes are illustrated in Figure 4 for the three reduced pressure values tested. The data for the polished $\left(R_{a}=0.17 \mu \mathrm{m}\right)$ and roughened $\left(R_{a}=1.37 \mu \mathrm{m}\right)$ tubes in $\mathrm{R}-134 \mathrm{a}$ has been presented previously in Bock et al. [26]. All surfaces tested showed typical constant power law relationships with linearly increased HTCs as the heat flux was increased on a log-log plot. The polished and LbL surfaces had the lowest HTCs overall. They had similar HTCs at the lowest reduced pressure value of 0.034 , but as the reduced pressure increased, the polished surface gradually outperformed the LbL surface. The roughened and $\mathrm{CuO}$ surfaces generally had the second-highest and third-highest HTCs. However, at the higher reduced pressure values of 0.086 and 0.160 , the $\mathrm{CuO}$ surface HTCs matched and at times surpassed the HTCs of the roughened surface at the upper end of the heat flux range tested. The nanoFLUX surface was associated with the highest HTCs at all reduced pressure values tested.

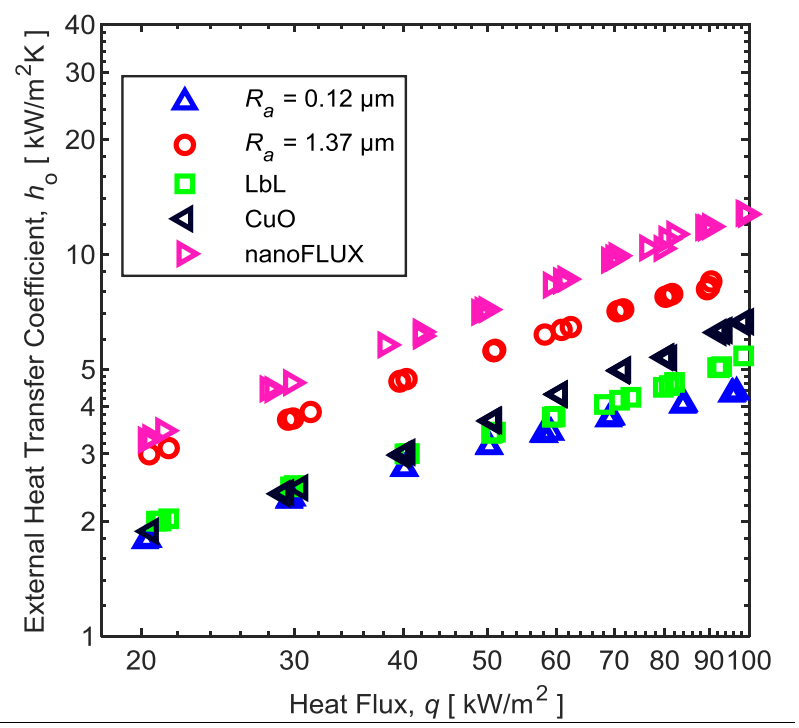

(a) R-245fa, $20^{\circ} \mathrm{C}, p_{r}$ of 0.034

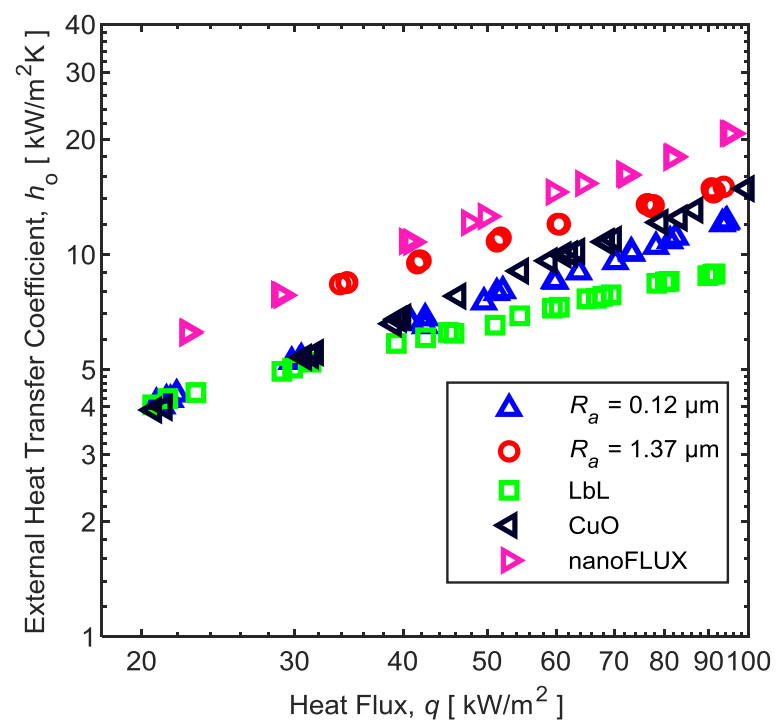

(b) R-134a, $5^{\circ} \mathrm{C}, p_{r}$ of 0.086

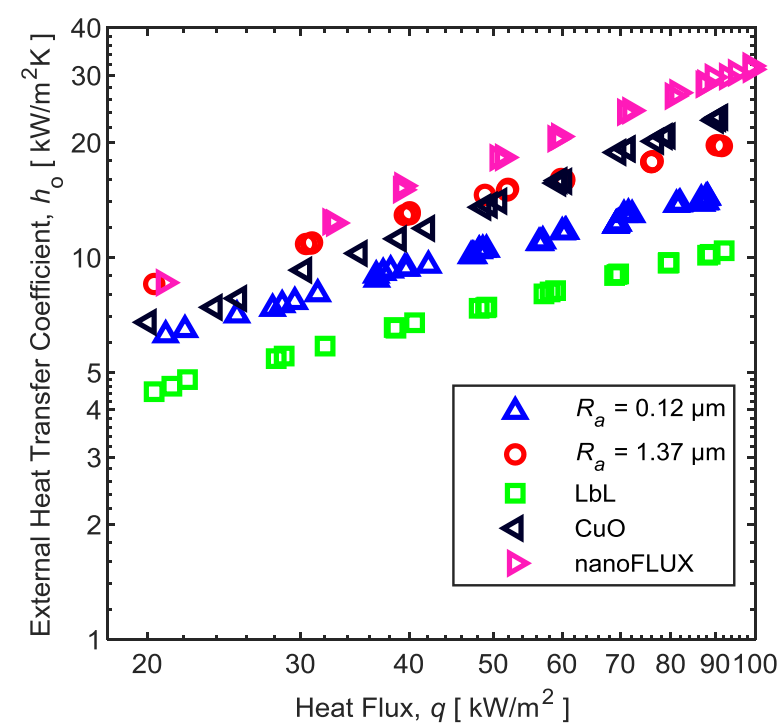

(c) R-134a, $25^{\circ} \mathrm{C}, p_{r}$ of 0.160

Figure 4: Heat transfer performance as a function of heat flux (polished and roughened R-134a data from Bock et al. [26])

Figure 5 illustrates the heat transfer performance of the surfaces relative to the polished surface at the three reduced pressure values tested. The roughened surface outperformed the polished surface by between 60 and $100 \%$ at the lowest 
reduced pressure value, and by approximately $40 \%$ at the higher reduced pressure values. The LbL surface slightly outperformed the polished surface at the lowest reduced pressure value of 0.034 by between 5 and $20 \%$. At the higher reduced pressure values, the LbL surface had up to $30 \%$ lower HTCs than the polished surface. The CuO surface performed similarly to the polished surface at low heat fluxes, while at higher heat fluxes, the CuO HTCs were higher than the HTCs of the polished surface by up to $50 \%$.

The nanoFLUX surface outperformed the polished surface over the heat flux range tested by between 80 and $200 \%$ at the lowest reduced pressure value and by approximately 40 to $100 \%$ at the higher reduced pressure values. The nanoFLUX surface generally outperformed the roughened surface by up to $50 \%$ across the range of test conditions, but the nanoFLUX and roughened surfaces had similar HTCs at the lower ends of the heat flux range tested.

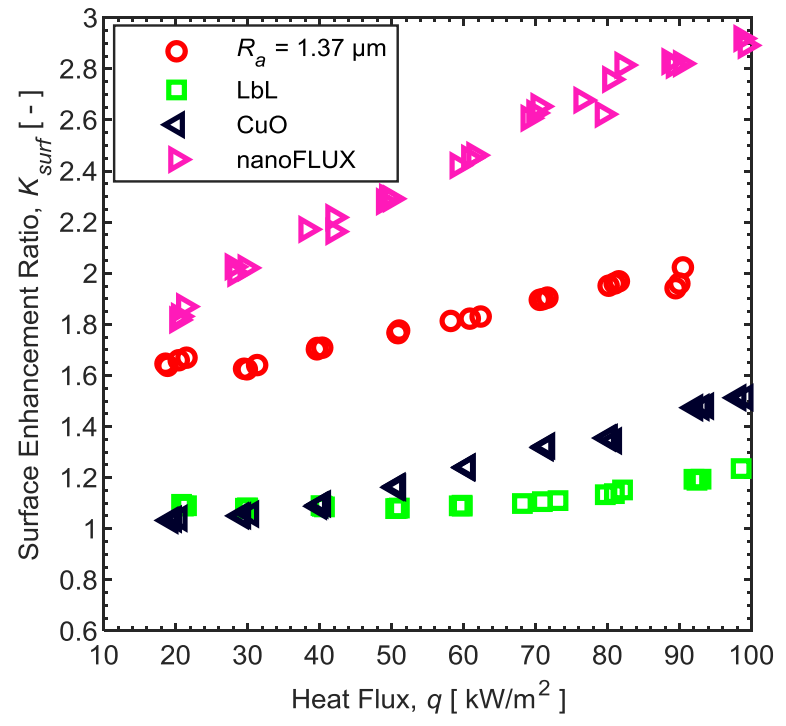

(a) R-245fa, $20^{\circ} \mathrm{C}, p_{r}$ of 0.034

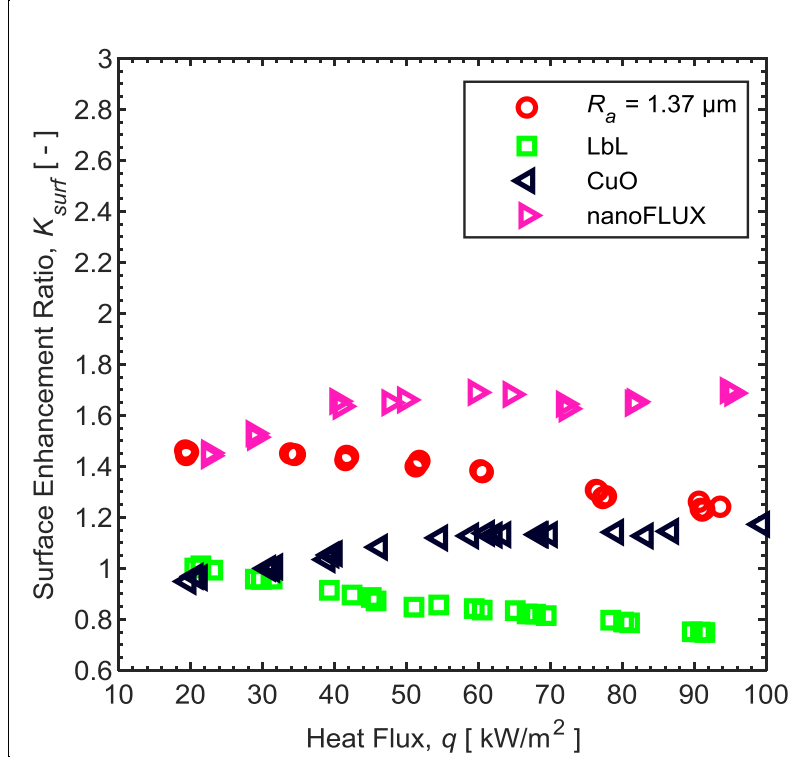

(b) R-134a, $5^{\circ} \mathrm{C}, p_{r}$ of 0.086

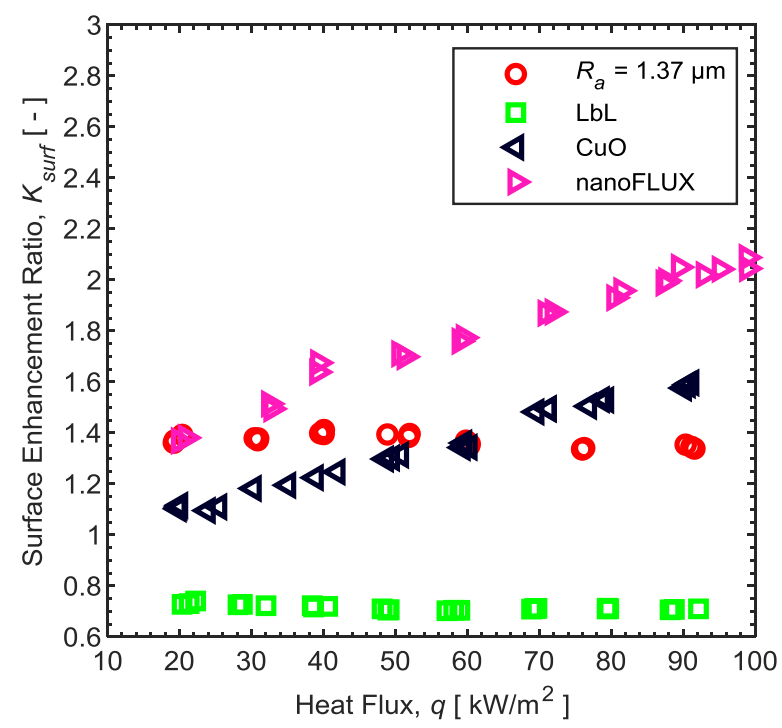

(c) R-134a, $25^{\circ} \mathrm{C}, p_{r}$ of 0.160

Figure 5: Heat transfer performance relative to polished plain tube

It can be noted in Figure 5 that the sensitivity of the HTCs of the surfaces to changes in heat flux varied relative to the polished surface and so was further quantified by determining the gradient of the data specifically by fitting the power law relation, $h_{o}=a q^{m}$, to the data in Figure 4 to determine the exponent, $m$. The results are shown in Figure 6 , where it can be seen that the roughened, polished and LbL surfaces were less sensitive, particularly at a reduced pressure of 0.16 , while the nanoFLUX and $\mathrm{CuO}$ surfaces were most sensitive to applied heat fluxes. 
Previous studies showed that heat flux sensitivity measured through the exponent, $m$, increased as the surface roughness decreased. This was thought to be because smoother surfaces had a greater number of smaller nucleation cavities that were only activated at higher heat fluxes [42]. Thus, the $\mathrm{CuO}$ and nanoFLUX surfaces could have a larger number of smaller cavities compared to the LbL, polished and roughened surfaces that where only activated at higher heat fluxes and so increased the at higher heat fluxes.

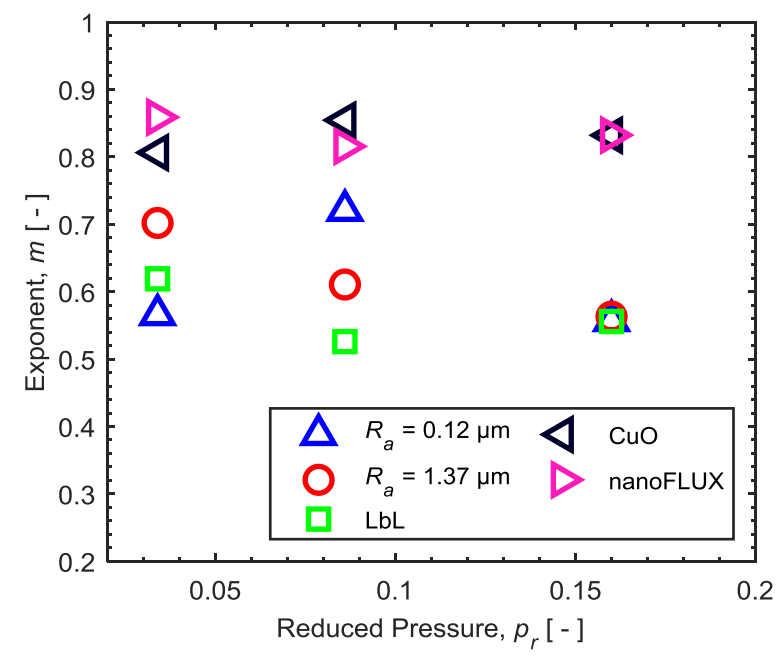

Figure 6: Fitted exponent, $m$, as a function of the reduced pressure

The influence of the different refrigerant properties and saturation temperatures can be captured using reduced pressure. The HTCs, as a function of the reduced pressure, are illustrated in Figure 7 at a heat flux of $50 \mathrm{~kW} / \mathrm{m}^{2}$ on a log-log plot. Both plain and nanostructured tubes showed similar sensitivities to changes in reduced pressure on the logarithmic plot, indicating a common power relationship for all the surfaces involved. Similar trends were seen at higher and lower heat fluxes. This is in contrast to the findings of Zimmermann et al. [23], where the HTCs measured on a nanowire surface boiling in FC-72 were practically independent of changes in saturation pressure (and thus changes in reduced pressure).

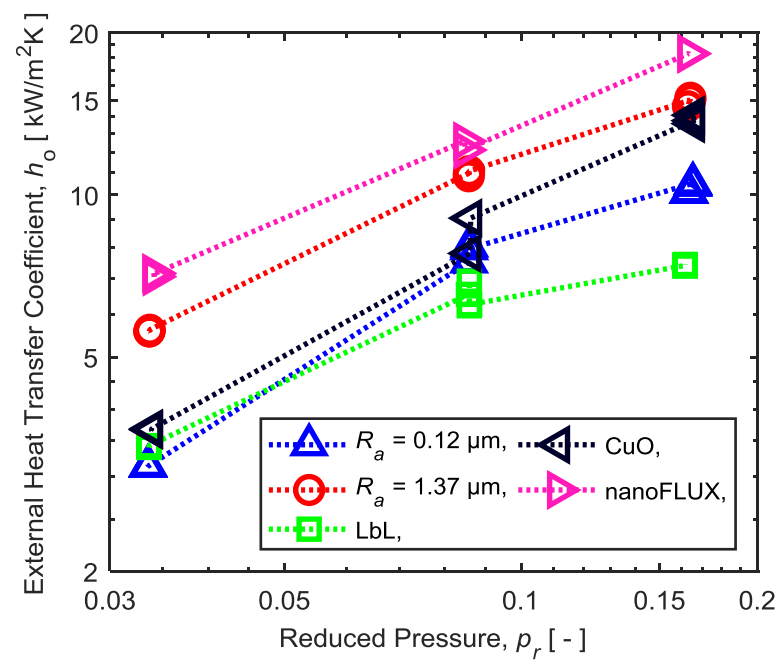

Figure 7: HTCs of surfaces as a function of reduced pressure at $50 \mathrm{~kW} / \mathrm{m}^{2}$

\subsection{Nucleation site density}

Images from a high-speed video camera taken with the aim of illustrating the differences in nucleation site density are shown in Figure 8, while the nucleation site densities measured from such videos are listed in Table 2.

The roughened surface had five times the nucleation site density than that of the polished surface, and the LbL surface had a $20 \%$ greater nucleation site density than that of the polished surface. The improved HTCs of the roughened and LbL surfaces at $20 \mathrm{~kW} / \mathrm{m}^{2}$ in R-245fa at $20^{\circ} \mathrm{C}$ relative to the polished surface can thus likely be accounted for by these greater nucleation site densities because bubble nucleation is known to improve heat transfer [3]. 
The nanoFLUX surface had a higher nucleation site density than the other nanostructured surfaces, showing that part of its improved heat transfer performance over other nanostructured surfaces was due to a rougher microstructure.

Table 2: Nucleation site density of surfaces in R-245fa at $20^{\circ} \mathrm{C}\left(p_{r}\right.$ of 0.086$)$ at $20 \mathrm{~kW} / \mathrm{m}^{2}$

\begin{tabular}{lcc}
\hline Surface & $\begin{array}{c}\text { Nucleation site } \\
\text { density, } \\
n\end{array}$ & $\begin{array}{c}\text { Nucleation sites relative } \\
\text { to polished surface, } \\
n / n_{\text {pol }} \\
{[-]}\end{array}$ \\
\hline Polished & $1.4 \times 10^{5}$ & 1 \\
Roughened & $6.9 \times 10^{5}$ & 4.9 \\
LbL & $1.7 \times 10^{5}$ & 1.2 \\
CuO & $8.0 \times 10^{4}$ & 0.57 \\
nanoFLUX & $2.8 \times 10^{5}$ & 2.0 \\
\hline
\end{tabular}

The $\mathrm{CuO}$ surface had approximately $60 \%$ of the nucleation sites of the polished surface, despite yielding slightly higher HTCs under these conditions. Similarly, the nanoFLUX surface had approximately $40 \%$ of the nucleation sites of the roughened surface, despite outperforming the HTCs of the roughened surface under these conditions by approximately $10 \%$. Therefore, both the $\mathrm{CuO}$ and nanoFLUX surfaces had fewer nucleation sites than the sandpapered surfaces of similar or lower HTCs.

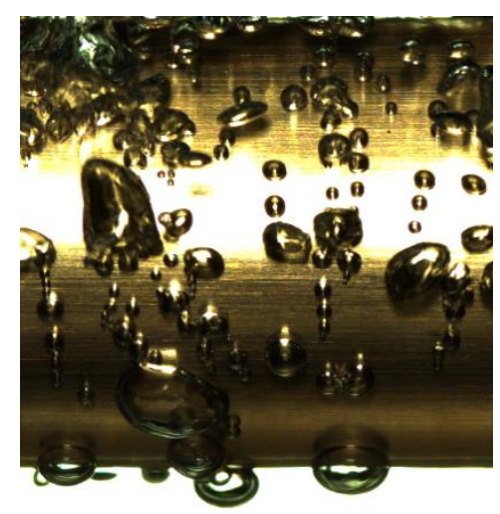

(a) Polished

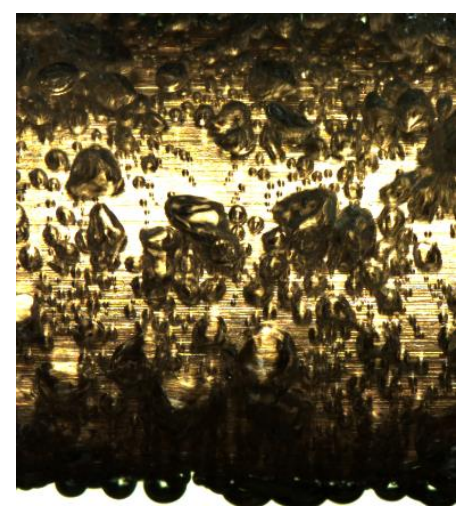

(b) Roughened

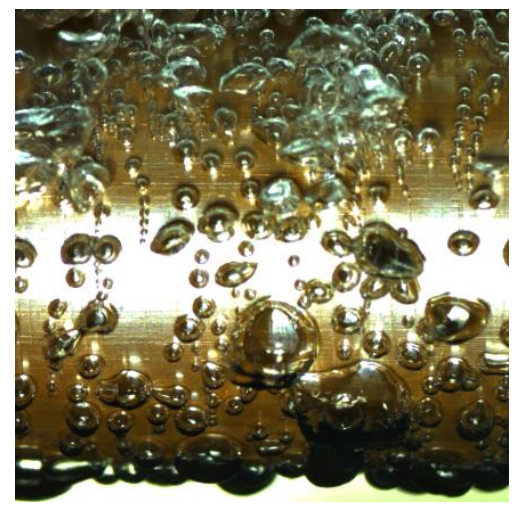

(c) $\mathrm{LbL}$

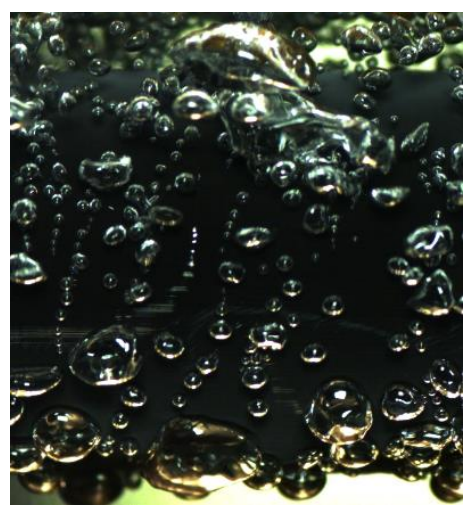

(d) $\mathrm{CuO}$

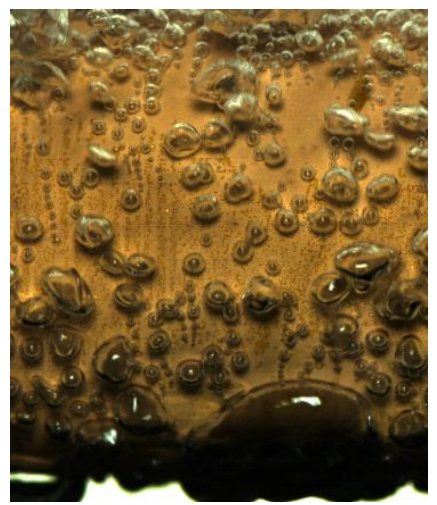

(e) nanoFLUX

Figure 8: Images of boiling surfaces at $20 \mathrm{~kW} / \mathrm{m}^{2}$ in R-245fa at $20^{\circ} \mathrm{C}\left(p_{r}\right.$ of 0.086$)$

Physically speaking, this demonstrates that the outside boiling site density is not the heat transfer enhancement mechanism, and thus one needs to look inside the coating for an answer. As described in Thome [2], the single-phase heat transfer from the flow of liquid into and out of the porous coating through its nano-sized channels, pumped by 
the bubbles, may be the main heat transfer enhancement mechanism, where one can imagine the very high laminar flow heat transfer coefficients for liquid passing through such small passages. For example, considering that simulations suggest Nusselt numbers for laminar flow convective heat transfer of water in nanochannels in the approximate range of 2 to 5 [44,45], an estimated pore size of $2 \mu \mathrm{m}$ gives a possible range of HTCs of approximately 9 to $20 \mathrm{~kW} / \mathrm{m}^{2} \mathrm{~K}$ for R-134a at $5{ }^{\circ} \mathrm{C}$. Furthermore, the $\mathrm{CuO}$ surface roughness ratio has been previously estimated to be in the range of 3 to $5[9,10]$ and the nanoFLUX surface likely has an even higher roughness ratio based on the SEM images of the nanostructures. This illustrates how single phase heat transfer within the porous nanostructures as a result of capillary pumping could significantly contribute to the overall external HTC.

A further possible enhancement mechanism is the evaporation of liquid wicked underneath the nucleating bubbles. Rahman et al. [13] showed that the $\mathrm{CuO}$ coating had reduced dryout under the nucleating bubble footprint compared with an uncoated surface which contributed an additional flux pathway. The authors suggested that this was caused by the capillary flow of liquid underneath the bubbles induced by the nanostructures. This additional thin film evaporation would eject a much higher flow of vapour and bubbles from the outside surface. Analysis of the bubble frequency and size is thus recommended for future study as it would provide evidence as to whether the single phase or two phase enhancement mechanisms described here were the dominant enhancement.

These mechanisms rely on capillary pumping, which is plausible if one considers the SEM images from Figure 2, the AFM images from Figure 3 and the isothermal wicking tests discussed previously, because both the $\mathrm{CuO}$ and nanoFLUX surfaces consisted of a mat of fibrous extrusions, which created a porous structure, while the polished, roughened and LbL surfaces did not. While refrigerants have a lower capillary action than water due to lower surface tensions, the $\mathrm{CuO}$ and nanoFLUX surfaces still wicked the refrigerants, as confirmed by the isothermal wicking behaviour seen. Both the $\mathrm{CuO}$ and nanoFLUX nanostructures are thus suggested to induce capillary flow within the porous layer while the non-wicking surfaces do not.

\subsection{Critical heat flux}

The CHF was reached in three instances of testing, as illustrated in Figure 9. As the wall superheat was raised, the heat flux reached a maximum, after which film boiling could be seen by visual observation to start at the heating water inlet end of the tube. Thereafter, as the wall superheat was increased further, film boiling spread along the length of the tube, resulting in a rapid decrease in the measured HTC. The experimental equipment employed was not designed with such high wall superheats in mind. Therefore, the fluxes necessary to reach the CHF of the other surfaces could not be obtained due to their low HTCs. The CHFs recorded were expected to be lower than those of a plain cylindrical surface based on the prediction of Lienhard and Dhir [46], as shown in Table 3, with CHFs between 24 and $51 \%$ lower than the predicted CHF of a plain surface.

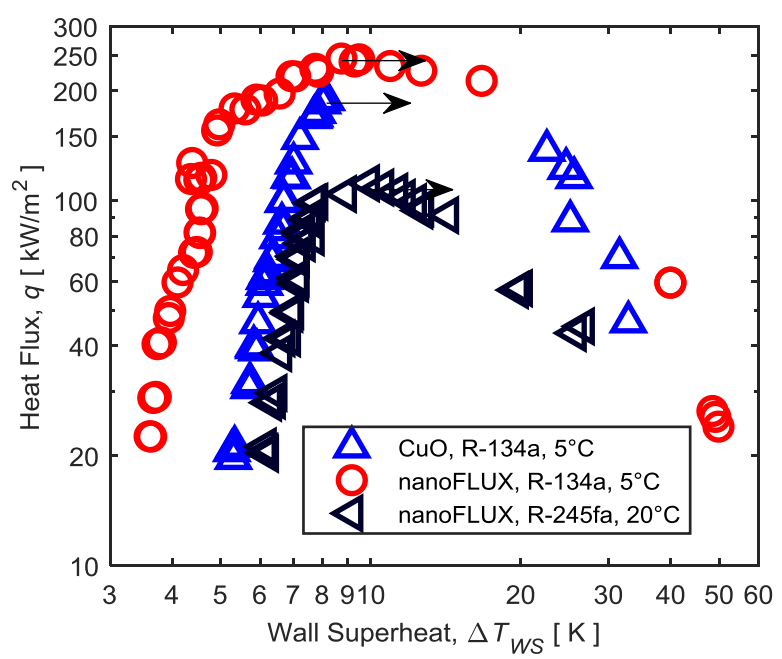

Figure 9: The CHF seen in the pool boiling of nanoFLUX and CuO tubes. The CHF point is indicated with arrows.

As discussed earlier, the CHF of a plain surface is generally improved by the addition of nanostructures that are wickable and wettable when boiling water, and researchers have recorded improvements for organic fluids in CHF in pool boiling conditions due to the presence of nanostructures $[12,19,20]$. However, some studies of organic fluid pool 
boiling [23] and flow boiling [22,24] have found that the CHF decreased due to the presence of nanostructures, despite good wettability of the surface by the organic fluids (contact angles $<25^{\circ}$ ), as is the case in this study.

The reason for the lowered CHF may be that the wettability of organic fluids such as R-134a and R-245fa is significantly reduced at high heat fluxes through the trapping of vapour in suitable nanostructures (such as the nanoFLUX and $\mathrm{CuO}$ surfaces), causing the surface to switch to a Cassie-Baxter wetting state and so cause an early onset of CHF. Table 1 shows that the water-in-air contact angles for the $\mathrm{CuO}$ and nanoFLUX surfaces can operate in the Cassie-Baxter state under suitable conditions. Unfortunately, previous authors who experienced early onset of the CHF of these surfaces compared with that of plain surfaces when boiling organic fluids [22-24] did not take water contact angle tests on aged surfaces to indicate whether the surfaces could support wetting in the Cassie-Baxter state.

Such behaviour may be more likely for organic fluids than for water because organic fluids should not benefit as much from the nanostructure-induced wicking observed in water CHF studies. The lower wickability of organic fluids compared with that of water is not only evident from wicking studies [22,24], but from Washburn's equation [47], where the ratio of surface tension to viscosity is shown to be important to capillary flow, where water at $100{ }^{\circ} \mathrm{C}$ (the most common test condition for water CHF studies) has a surface tension-to-viscosity ratio of almost five times that of R-134a at $5{ }^{\circ} \mathrm{C}$.

Table 3: Measured and predicted CHFs

\begin{tabular}{lccc}
\hline \multicolumn{1}{c}{ Conditions } & $\begin{array}{c}\text { Measured } \\
\mathrm{CHF}, \\
q_{C H F, \text { measured }} \\
{\left[\mathrm{kW} / \mathrm{m}^{2}\right]}\end{array}$ & $\begin{array}{c}\text { Predicted CHF [46] } \\
\text { of a plain cylindrical } \\
\text { surface, } \\
q_{\text {CHF,plain }} \\
{\left[\mathrm{kW} / \mathrm{m}^{2}\right]}\end{array}$ & $\begin{array}{c}\text { CHF relative to plain } \\
\text { surface, } \\
q_{C H F, \text { measured }}\end{array}$ \\
\hline $\begin{array}{l}q_{C H F, \text { plain }} \\
\text { nanoFLUX surface, }\end{array}$ & 112 & 227 & 0.49 \\
$\begin{array}{l}\text { nanoFLUX surface, } \\
\text { R-134a at 5 }{ }^{\circ} \mathrm{C}\end{array}$ & 245 & 324 & 0.76 \\
$\begin{array}{l}\text { Cu0 surface, } \\
\text { R-134a at 5 }{ }^{\circ} \mathrm{C}\end{array}$ & 189 & 324 & 0.58 \\
\hline
\end{tabular}

The lower latent heat of vaporisation, $h_{f g}$, of organic fluids, with R-134a having an $h_{f g}$ of $1947 \mathrm{~kJ} / \mathrm{kg}$ at $5{ }^{\circ} \mathrm{C}$, while water has an $h_{f g}$ of $2256 \mathrm{~kJ} / \mathrm{kg}$ at $100{ }^{\circ} \mathrm{C}$ [37], may also play a part in them being more likely to switch to the CassieBaxter state at higher heat fluxes than for water, as it allows for quicker evaporation and dryout of the wicked liquid. The lower latent heat of vaporisation of organic fluids will also produce greater volumes of vapour than for water at the same heat flux, which may make it more susceptible to nanostructure vapour entrapment, although this will also cause greater evaporative-induced negative pressure that should, in turn, drive wicking [6].

If this reduced wetting hypothesis is accepted, the CHF trends in Table 3, combined with data from previous studies $[22,24]$, suggest that the sooner the wicking capabilities of the surface can be overcome as heat flux rises, the sooner the onset of CHF will occur. In this study, the nanoFLUX surface with its larger nanostructures had a higher CHF than that of the $\mathrm{CuO}$ in R-134a at $5^{\circ} \mathrm{C}$. A similar trend was found in the studies of Shin et al. [24] and Kim et al. [22], where longer nanowires had higher CHFs in the flow boiling of FC-72, while all were below the CHF value of the respective plain surface. These larger nanostructured surfaces were expected to induce more wicking, as shown in wicking studies by Kim et al. [22], considering that a greater pore radius drives greater capillary flow in terms of Washburn's equation [47]. Furthermore, the CHF in this study was shown to be lower for R-245fa than for R-134a with the nanoFLUX surface. The R-245fa was expected to support less wicking than R-134a due to a lower surface tension-to-viscosity ratio ( $34 \mathrm{~m} / \mathrm{s}$ for R-245fa compared with $43 \mathrm{~m} / \mathrm{s}$ for R-134a). Therefore, this hypothesis suggests that, as heat flux is increased during boiling, the quicker the wicking abilities of the surface are overpowered, the quicker the surface can switch to a Cassie-Baxter state and the CHF be initiated.

\section{Conclusions}

The purpose of this study was to investigate experimentally the heat transfer characteristics of nanostructured and plain copper horizontal tubes in the saturate pool boiling of refrigerants. A smooth polished copper tube and a roughened copper tube were tested, together with three different nanostructured surfaces that were applied to 
polished copper tubes, all with an outer diameter of $19.05 \mathrm{~mm}$. The nanostructured surfaces were created through three different processes: (i) a deposition process where nanoparticles were applied layer-by-layer,(ii) a chemical oxidation process that produced $\mathrm{CuO}$ structures, and (iii) a commercially available process (nanoFLUX $\odot$ ). The heat transfer coefficients (HTCs) of the saturated pool boiling of refrigerants at three reduced pressure values of 0.034 $\left(\mathrm{R}-245 \mathrm{fa}\right.$ at $\left.20^{\circ} \mathrm{C}\right), 0.086\left(\mathrm{R}-134 \mathrm{a}\right.$ at $\left.5{ }^{\circ} \mathrm{C}\right)$ and $0.160\left(\mathrm{R}-134 \mathrm{a}\right.$ at $\left.25^{\circ} \mathrm{C}\right)$ were measured over a heat flux range from 20 to $100 \mathrm{~kW} / \mathrm{m}^{2}$, followed by a further increase in heat flux in an attempt to reach critical heat flux.

The plain and nanostructured surfaces displayed linearly increasing HTCs as the heat flux was increased on a log$\log$ plot. The $\mathrm{CuO}$ and nanoFLUX surfaces were more sensitive to changes in heat flux than the polished, roughened and LbL surfaces, with improved heat transfer at higher heat fluxes than those of the other surfaces. This finding could be due to a larger population of small nucleation sites.

The LbL surface had up to 20\% higher HTCs than those of the polished surface at the lowest reduced pressure and down to $20 \%$ lower HTCs at the highest reduced pressure tested. The CuO surface performed similarly to the polished surface at low heat fluxes $\left(20 \mathrm{~kW} / \mathrm{m}^{2}\right)$, but outperformed the polished surface by approximately $60 \%$ at high heat fluxes $\left(100 \mathrm{~kW} / \mathrm{m}^{2}\right)$ in terms of HTCs.

Furthermore, it was found that the nanoFLUX nanostructured surface produced the highest HTCs, with measured HTCs between 40 and $200 \%$ higher than those of a polished copper surface, and between 0 and $50 \%$ higher than those of a roughened copper surface.

The nanoFLUX surface had a greater nucleation site density compared to other nanostructured surfaces, which suggested a rougher microstructure that contributed to its improved heat transfer. When boiling $\mathrm{R}-245 \mathrm{fa}$ at $20^{\circ} \mathrm{C}$ at $20 \mathrm{~kW} / \mathrm{m}^{2}$, the nanoFLUX and CuO surfaces had fewer nucleation sites than those of sandpapered surfaces of similar heat transfer performance and thus suggests that the nanoFLUX and CuO surfaces had an additional unique heat transfer mechanism compared with sandpapered surfaces. This was possibly linked to capillary wicking of liquid inside the nanochannels of the porous coatings driven by the external bubble pumping, which contributed to enhanced single-phase liquid superheating by the flow of liquid through the nano-sized channels or reduced dryout and increased microlayer evaporation underneath the nucleating bubbles. Analysis of the bubble frequency and size is recommended for future studies to elucidate further the HTC enhancement mechanisms.

Finally, the measured CHF of the $\mathrm{CuO}$ and nanoFLUX surfaces was lower than that expected for a plain surface. It was suggested that the early onset of CHF for boiling over the $\mathrm{CuO}$ and nanoFLUX surfaces may be due to vapour trapped in the fibrous nanostructure, resulting in reduced wetting in the Cassie-Baxter state.

\section{Credit authorship contribution statement}

Bradley D. Bock: Conceptualisation, methodology, validation, formal analysis, investigation, data curation, visualisation, writing - original draft, project administration. Matteo Bucci: Conceptualisation, funding acquisition, resources, supervision, writing - review and editing. Christos N. Markides: Conceptualisation, funding acquisition, writing - review and editing. John R. Thome: Conceptualisation, methodology, funding acquisition, resources, supervision, writing - review and editing. Josua P. Meyer: Conceptualisation, methodology, funding acquisition, resources, supervision, writing - review and editing.

\section{Declaration of competing interest}

The authors declared that there is no conflict of interest.

\section{Acknowledgements}

This work was, in part, supported by the MIT International Science and Technology Initiatives (MISTI) programme under an MIT-Africa-Imperial College London seed fund grant, by the UK Department for International Development (DFID) through the Royal Society-DFID Africa Capacity Building Initiative and by the European Union's Horizon 2020 Research and Innovation Programme within the ThermaSMART network under the Marie Sklodowska-Curie Grant Agreement No. 778104. The authors would also like to acknowledge Dr Victor Voulgaropoulos for initiating and administering the MIT-Africa-Imperial College London seed fund grant, Dr Alexander Reip and Tim Bullen of Oxford nanoSystems and Chi Wang and Dr Bren Phillips at MIT for assistance with the coatings, and lastly Dr Dorette Kritzinger and Prof Jackie Nel at the University of Pretoria for assistance with the surface characterisation. 


\section{References}

[1] J. Dirker, D. Juggurnath, A. Kaya, E. A. Osowade, M. Simpson, S. Lecompte, S. M. A. Noori Rahim Abadi, V. Voulgaropoulos, A. O. Adelaja, M. Z. Dauhoo, A. Khoodaruth, S. O. Obayopo, O. T. Olakoyejo, M. K. Elahee, M. De Paepe, J. P. Meyer, and C. N. Markides, "Thermal energy processes in direct steam generation solar systems: Boiling, condensation and energy storage - A review," Frontiers in Energy Research, Review vol. 6, no. 147, 2019-March-05 2019.

[2] J. R. Thome, Enhanced boiling heat transfer. Taylor \& Francis, 1990.

[3] W. M. Rohsenow, J. P. Hartnett, and Y. I. Cho, Handbook of heat transfer. McGraw-Hill New York, 1998.

[4] D. E. Kim, D. I. Yu, D. W. Jerng, M. H. Kim, and H. S. Ahn, "Review of boiling heat transfer enhancement on micro/nanostructured surfaces," Experimental Thermal and Fluid Science, vol. 66, pp. 173-196, 2015/09/01/ 2015.

[5] C. S. Sujith Kumar, G. Udaya Kumar, M. R. Mata Arenales, C.-C. Hsu, S. Suresh, and P.-H. Chen, "Elucidating the mechanisms behind the boiling heat transfer enhancement using nano-structured surface coatings," Applied Thermal Engineering, vol. 137, pp. 868-891, 2018/06/05/ 2018.

[6] X. Li, I. Cole, and J. Tu, "A review of nucleate boiling on nanoengineered surfaces: The nanostructures, phenomena and mechanisms," International Journal of Heat and Mass Transfer, vol. 141, pp. 20-33, 2019/10/01/ 2019.

[7] J. Barber, D. Brutin, and L. Tadrist, "A review on boiling heat transfer enhancement with nanofluids," Nanoscale Research Letters, vol. 6, no. 1, p. 280, 2011/04/04 2011.

[8] M. Shojaeian and A. Koşar, "Pool boiling and flow boiling on micro- and nanostructured surfaces," Experimental Thermal and Fluid Science, vol. 63, pp. 45-73, 2015/05/01/ 2015.

[9] K.-H. Chu, Y. S. Joung, R. Enright, C. R. Buie, and E. N. Wang, "Hierarchically structured surfaces for boiling critical heat flux enhancement," Applied Physics Letters, vol. 102, no. 15, p. 151602, 2013.

[10] M. M. Rahman, E. Ölçeroğlu, and M. McCarthy, "Role of wickability on the critical heat flux of structured superhydrophilic surfaces," Langmuir, vol. 30, no. 37, pp. 11225-11234, 2014/09/23 2014.

[11] J. Kim, S. Jun, J. Lee, J. Godinez, and S. M. You, "Effect of surface roughness on pool boiling heat transfer of water on a superhydrophilic aluminum surface," Journal of Heat Transfer, vol. 139, no. 10, 2017.

[12] B. Liu, Z. Cao, Y. Zhang, Z. Wu, A. Pham, W. Wang, Z. Yan, J. Wei, and B. Sundén, "Pool boiling heat transfer of n-pentane on micro/nanostructured surfaces," International Journal of Thermal Sciences, vol. 130, pp. 386394, 2018/08/01/ 2018.

[13] M. M. Rahman, A. Kossolapov, J. H. Seong, J. Buongiorno, and M. Bucci, "Investigation of pool boiling heat transfer and CHF enhancement on nano-engineered surfaces using advanced diagnostics," in International Conference on Boiling and Condensation Heat Transfer, Nagasaki, Japan, 2018.

[14] E. Forrest, E. Williamson, J. Buongiorno, L.-W. Hu, M. Rubner, and R. Cohen, "Augmentation of nucleate boiling heat transfer and critical heat flux using nanoparticle thin-film coatings," International Journal of Heat and Mass Transfer, vol. 53, no. 1, pp. 58-67, 2010/01/15/2010.

[15] H. O'Hanley, C. Coyle, J. Buongiorno, T. McKrell, L.-W. Hu, M. Rubner, and R. Cohen, "Separate effects of surface roughness, wettability, and porosity on the boiling critical heat flux," Applied Physics Letters, vol. 103, no. 2, p. 024102, 2013.

[16] M. Tetreault-Friend, R. Azizian, M. Bucci, T. McKrell, J. Buongiorno, M. Rubner, and R. Cohen, "Critical heat flux maxima resulting from the controlled morphology of nanoporous hydrophilic surface layers," Applied Physics Letters, vol. 108, no. 24, p. 243102, 2016.

[17] V. Trisaksri and S. Wongwises, "Nucleate pool boiling heat transfer of TiO2-R141b nanofluids," International Journal of Heat and Mass Transfer, vol. 52, no. 5, pp. 1582-1588, 2009/02/01/2009.

[18] M. Ray, S. Deb, and S. Bhaumik, "Pool boiling heat transfer of refrigerant R-134a on TiO2 nano wire arrays surface," Applied Thermal Engineering, vol. 107, pp. 1294-1303, 2016/08/25/ 2016.

[19] Y. Im, Y. Joshi, C. Dietz, and S. S. Lee, "Enhanced boiling of a dielectric liquid on copper nanowire surfaces," International Journal of Micro-Nano Scale Transport, vol. 1, no. 1, pp. 79-96, 2010.

[20] G. Udaya Kumar, S. Suresh, M. R. Thansekhar, and P. Dinesh Babu, "Effect of diameter of metal nanowires on pool boiling heat transfer with FC-72," Applied Surface Science, vol. 423, pp. 509-520, 2017/11/30/2017.

[21] W. Wu, H. Bostanci, L. C. Chow, Y. Hong, M. Su, and J. P. Kizito, "Nucleate boiling heat transfer enhancement for water and FC-72 on titanium oxide and silicon oxide surfaces," International Journal of Heat and Mass Transfer, vol. 53, no. 9, pp. 1773-1777, 2010/04/01/ 2010.

[22] B. S. Kim, G. Choi, D. I. Shim, K. M. Kim, and H. H. Cho, "Surface roughening for hemi-wicking and its impact on convective boiling heat transfer," International Journal of Heat and Mass Transfer, vol. 102, pp. 1100-1107, 2016/11/01/ 2016. 
[23] M. Zimmermann, M. Heinz, A. Sielaff, T. Gambaryan-Roisman, and P. Stephan, "Influence of system pressure on pool boiling regimes on a microstructured surface compared to a smooth surface," Experimental Heat Transfer, pp. 1-17, 2019.

[24] S. Shin, G. Choi, B. S. Kim, and H. H. Cho, "Flow boiling heat transfer on nanowire-coated surfaces with highly wetting liquid," Energy, vol. 76, pp. 428-435, 2014/11/01/ 2014.

[25] C. G. Jothi Prakash and R. Prasanth, "Enhanced boiling heat transfer by nano structured surfaces and nanofluids," Renewable and Sustainable Energy Reviews, vol. 82, pp. 4028-4043, 2018/02/01/2018.

[26] B. D. Bock, J. P. Meyer, and J. R. Thome, "Falling film boiling and pool boiling on plain circular tubes: Influence of surface roughness, surface material and saturation temperature on heat transfer and dryout," Experimental Thermal and Fluid Science, vol. 109, p. 109870, 2019/12/01/ 2019.

[27] D. Gorenflo and D. B. R. Kenning, "Pool boiling (chapter H2)," in VDI Heat AtlasBerlin, Heidelberg: SpringerVerlag, 2010, pp. 757-792.

[28] M. Cooper, "Saturation nucleate pool boiling: A simple correlation," in Inst. Chem. Eng. Symp. Ser, 1984, vol. 86, no. 2, pp. 785-793, 1984.

[29] F. C.. Cebeci, Z. Wu, L. Zhai, R. E. Cohen, and M. F. Rubner, "Nanoporosity-driven superhydrophilicity: A means to create multifunctional antifogging coatings," Langmuir, vol. 22, no. 6, pp. 2856-2862, 2006/03/01 2006.

[30] Y. Nam and Y. S. Ju, "A comparative study of the morphology and wetting characteristics of micro/nanostructured $\mathrm{Cu}$ surfaces for phase change heat transfer applications," Journal of Adhesion Science and Technology, vol. 27, no. 20, pp. 2163-2176, 2013/10/01 2013.

[31] J. Drelich, E. Chibowski, D. D. Meng, and K. Terpilowski, "Hydrophilic and superhydrophilic surfaces and materials," Soft Matter, 10.1039/C1SM05849E vol. 7, no. 21, pp. 9804-9828, 2011.

[32] X. Yan, Z. Huang, S. Sett, J. Oh, H. Cha, L. Li, L. Feng, Y. Wu, C. Zhao, D. Orejon, F. Chen, and N. Miljkovic, "Atmosphere-mediated superhydrophobicity of rationally designed micro/nanostructured surfaces," ACS Nano, vol. 13, no. 4, pp. 4160-4173, 2019/04/23 2019.

[33] A. F. Stalder, T. Melchior, M. Müller, D. Sage, T. Blu, and M. Unser, "Low-bond axisymmetric drop shape analysis for surface tension and contact angle measurements of sessile drops," Colloids and Surfaces A: Physicochemical and Engineering Aspects, vol. 364, no. 1, pp. 72-81, 2010/07/20/ 2010.

[34] W. S. Rasband, "ImageJ," ed: Bethesda, MD, 1997.

[35] R. N. Wenzel, "Resistance of solid surfaces to wetting by water," Industrial \& Engineering Chemistry, vol. 28, no. 8, pp. 988-994, 1936.

[36] A. B. D. Cassie and S. Baxter, "Wettability of porous surfaces," Transactions of the Faraday Society, 10.1039/TF9444000546 vol. 40, no. 0, pp. 546-551, 1944.

[37] E. W. Lemmon, M. L. Huber, and M. O. McLinden, "NIST reference fluid thermodynamic and transport properties-REFPROP," NIST Standard Reference Database, vol. 23, p. v7, 2002.

[38] V. Gnielinski, "New equations for heat and mass-transfer in turbulent pipe and channel flow," International Chemical Engineering, vol. 16, no. 2, pp. 359-368, 1976.

[39] B. S. Petukhov, "Heat transfer and friction in turbulent pipe flow with variable physical properties," in Advances in Heat Transfer, vol. 6, J. P. Hartnett and T. F. Irvine, Eds.: Elsevier, 1970, pp. 503-564.

[40] P. F. Dunn, Measurement and data analysis for engineering and science, 2nd ed. CRC press, 2010.

[41] JCGM 100: 2008, "Evaluation of measurement data: Guide for the expression of uncertainty in measurement," 2008.

[42] J. Jabardo, "An overview of surface roughness effects on nucleate boiling heat transfer," The Open Conservation Biology Journal, vol. 2, no. 1, 2010.

[43] J. H. Lienhard, A heat transfer textbook. Courier Corporation, 2013.

[44] S. Ge, Y. Gu, and M. Chen, "A molecular dynamics simulation on the convective heat transfer in nanochannels," Molecular Physics, vol. 113, no. 7, pp. 703-710, 2015/04/03 2015.

[45] W. A. Khan and M. M. Yovanovich, "Analytical Modeling of Fluid Flow and Heat Transfer in Microchannel/Nanochannel Heat Sinks," Journal of Thermophysics and Heat Transfer, vol. 22, no. 3, pp. 352359, 2008.

[46] J. Lienhard and V. K. Dhir, "Extended hydrodynamic theory of the peak and minimum pool boiling heat fluxes," NASA Report CR-2270, 1973.

[47] E. W. Washburn, "The dynamics of capillary flow," Physical Review, vol. 17, no. 3, pp. 273-283, 03/01/ 1921. 